\title{
A topographic origin for double-ridge features in visible imagery of ice divides in Antarctica
}

\author{
A. H. GoOdwin \\ Department of Geography, University of Aberdeen, Aberdeen AB2 9UF, Scotland
}

D. G. Vaughan

British Antartic Survey, Natural Environment Research Council, Madingley Road, Cambridge CB3 OET, England

\begin{abstract}
The appearance of double-ridge features on visible imagery of the ice divides of Antarctic ice rises has often been noted but, largely due to a lack of adequate ground truth, their origins have remained enigmatic. We present several examples of ice rises and other isolated ice-flow centres that apparently show double ridges. We investigate one of these in particular: Fletcher Promontory, Antarctica. A digital-elevation model (DEM) of the summit region is derived from surface profiles obtained using the Global Positioning System (GPS) and this is correlated with Landsat MSS satellite imagery. Precise registration is achieved by correlating imagebrightness values with surface slope calculated along the direction of the Sun azimuth in the image. Using a simple bi-directional relation, the DEM data are used to model the Landsat image. We therefore demonstrate that the double ridge is a product of a subtle concavity parallel to the ridge and is unlikely to be dependent on other factors. This concavity is not predicted by steady-state models of ice divides and so we suggest that the ridge may not be in a steady-state but responding to changes in the glaciological boundary conditions. We speculate that this may be an indication of ongoing migration of the ice divide.
\end{abstract}

\section{INTRODUCTION}

In the remote polar regions, satellite imagery has provided an invaluable source of data for mapping and glaciological interpretation. High-resolution visible imagery depicts many glaciological features such as relict flowlines, crevasses, grounding lines, ice streams, ice rumples and ice rises that help us understand the largescale flow of the ice sheet (Vaughan and Doake, 1992) but our understanding of the processes of image formation is far from complete.

Embedded within large-scale flow of the ice sheet are other flow centres producing their own radial flow patterns. A common example of this behaviour occurs where a floating ice shelf separates to flow round a grounded section, thus forming an ice rise which generates its own independent flow pattern. The flow is dynamically separated from the general flow, often by a zone of crevassing (Hall and Martinec, 1985). Distinct by definition but similar in glaciological style are peninsulas, connected to the main ice sheet by only narrow isthmuses but otherwise surrounded by open sea. These are also effectively isolated from the main flow and generate their own radial flow regime. There are other examples of isolated radial flows within the grounded ice sheet that do not fall easily into either definition; one such is Fletcher Promontory (Fig. 1), the primary subject of this study. Although Fletcher Promontory is not entirely surrounded

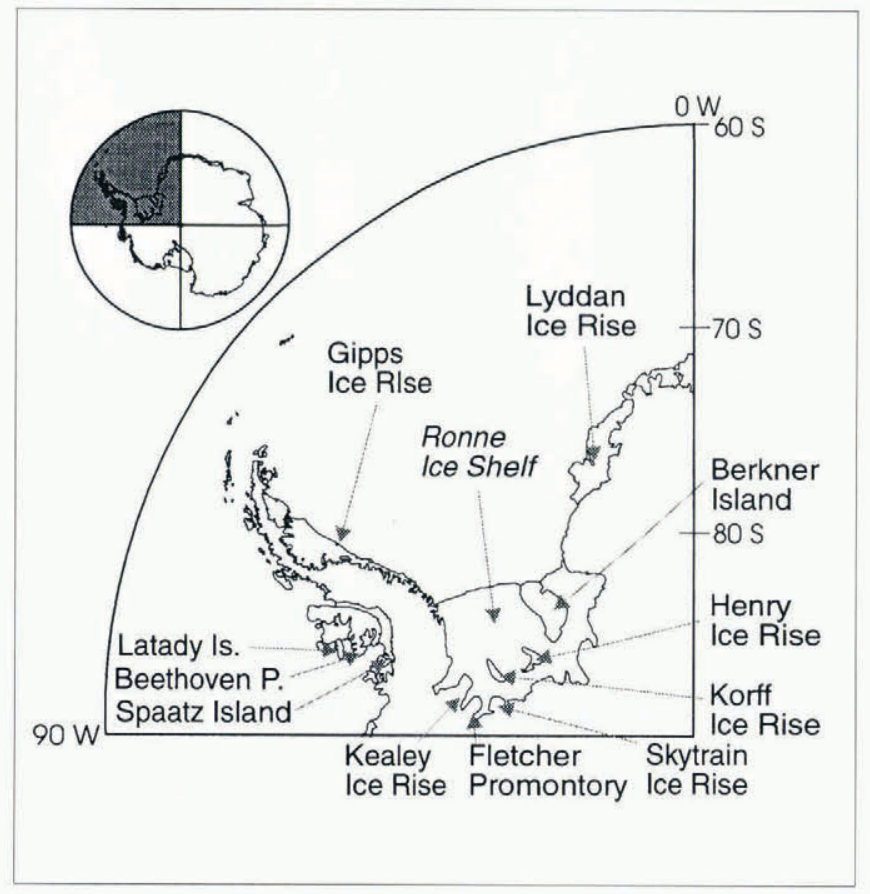

Fig. 1. Location diagram and examples of ice rises and peninsulas in one sector of Antarctica. Berkner Island (the largest) is approximately $360 \mathrm{~km}$ by $140 \mathrm{~km}$ and rises to over $700 \mathrm{~m}$ above the surrounding ice shelf; in contrast, Gipps Ice Rise measures less than $15 \mathrm{~km}$ by $10 \mathrm{~km}$ with its summit $250 \mathrm{~m}$ above the ice shelf. 
by ice shelf, and so is not strictly an ice rise, it is isolated from the ice streams around it, giving good reason to consider it as glaciologically similar. The same argument applies for Fletcher Promontory's neighbour, Kealey Ice Rise.

Isolated flow systems of all types are of particular glaciological interest because they offer simple conditions for studying the mechanisms of ice deformation giving small-scale and more quickly evolving analogues of complete ice sheets.

Satellite imagery commonly shows distinct linear ridges within these isolated radial flows, indicating the ice divides (the "watersheds" in ice flow). Martin (1976) investigated what appeared to be anomalous ridges on satellite imagery and concluded that these were not produced by ice deformation but by an unusual accumulation process across the ice divide. Martin and Sanderson (1980) continued this work using ground truth from Gipps Ice Rise, Antarctica. Surface surveys showed that the crest was, in fact, marginally flatter than the simple theory suggested and did not show the ridges that they had interpreted from the imagery. Martin and Sanderson suggested that the apparent ridge in the imagery was the result of different properties of the surface snow across the ridge rather than simply a result of the topography. In particular, they suspected a change in crystal orientation. Sadly, digital image-processing techniques were not available to Martin and Sanderson and so they made no direct comparison between the measured topography and the image representation; their conclusions were based on visual inspection of photographically reproduced images, a necessarily inexact method.

Lucchitta and others (1987) noted that on satellite imagery of a few ice-rise crests a second ridge running roughly parallel to the first can be observed. Three examples are shown in Figure 2. Two pieces of evidence indicate that the double ridges are not artifacts of imaging but result from unusual conditions on the snow surface. First, it was noted by Lucchitta and others (1987) that the double ridges are long-lived, appearing over the same ice rises in different years. Secondly, double ridges have been seen in images collected by a variety of sensors: Landsat MSS, Landsat TM and SPOT. A survey of Landsat imagery has shown double ridges over many other local divides (e.g. Latady Island, Spaatz Island and Lyddan Ice Rise), while other divides show only a singleridge feature (e.g. Skytrain Ice Rise, Beethoven Peninsula, Henry Ice Rise and Berkner Island). It is the origin of these double ridges that is the subject of the present study.

\section{REFLEGTIVE PROPERTIES OF SNOW}

Visible imagery contains two signals relating to the surface: (i) spectral-reflectivity variations related to intrinsic properties of the materials within the scene, and (ii) variations due to the topography (Eliason and others, 1981). Over the relatively homogeneous snow cover of Antarctica, albedo can be relatively constant and variations in image brightness are often primarily due to slope. The ice divides we are considering generally have surface slopes less than $2^{\circ}$. Since Landsat imagery is not normally collected at Sun elevations of less than $10^{\circ}$

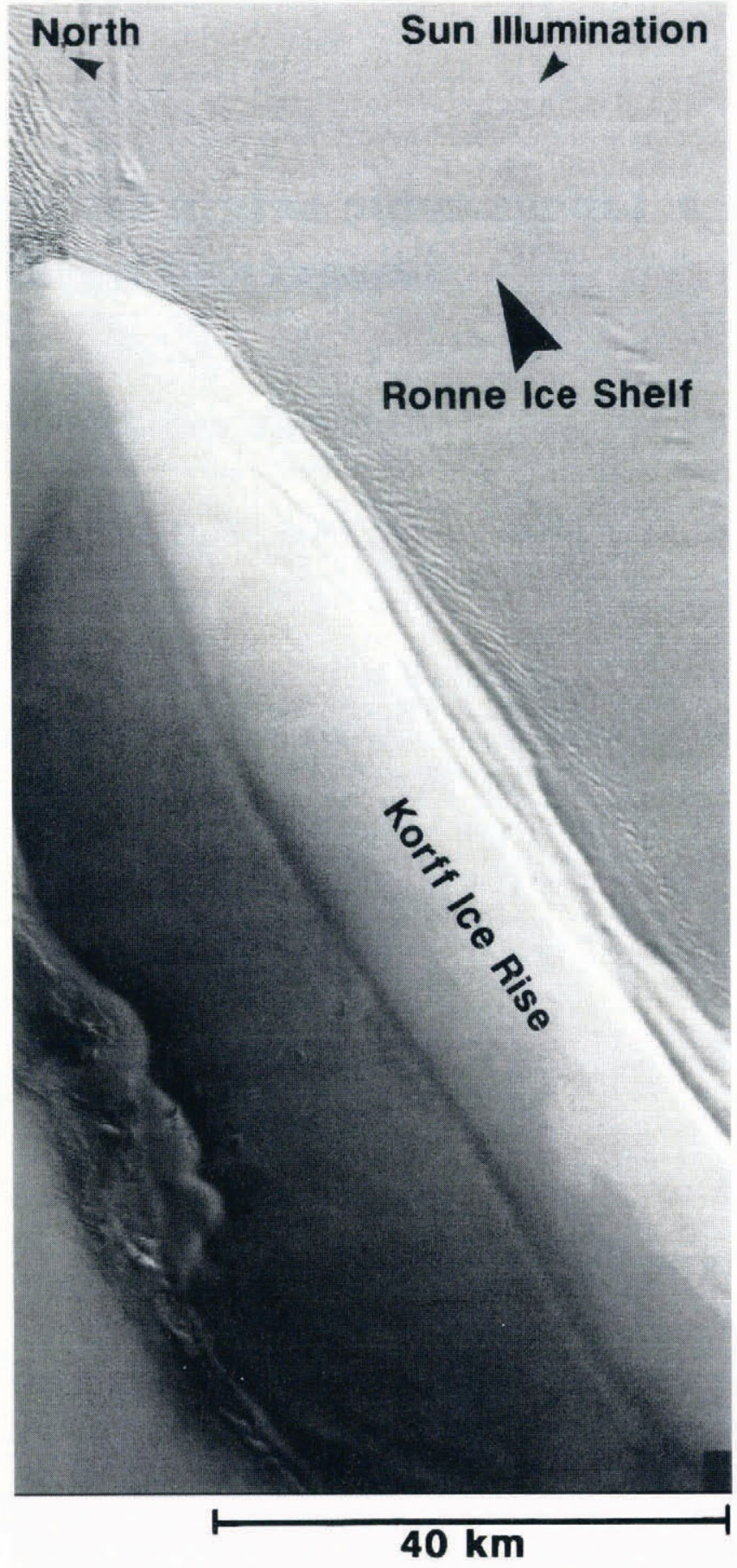

Fig. 2. Examples of imagery showing double-ridge features over ice rises. General ice-flow directions are indicated by large arrows. (Landsat imagery reproduced by courtesy of EOSAT.) a. Sub-scene of Landsat MSS image of Korff Ice Rise (path/row 208/118, 4 February 1974). The image has been processed to show principal component 1 for the 4 MSS bands and contrast stretched by histogram equalization.

above the horizontal (U.S. Geological Survey, 1979), it is clear the expression of these ice divides in the imagery does not result from direct shadowing. Rather, the topography is expressed by the process of shading and is governed by the bi-directional reflectance function (Warren, 1982; Dowdeswell and McIntyre, 1987; Vaughan and others, 1988). The exact expression of the double-ridge features will, thus, be dependent on the Sun azimuth and to a lesser extent the Sun elevation. With an 


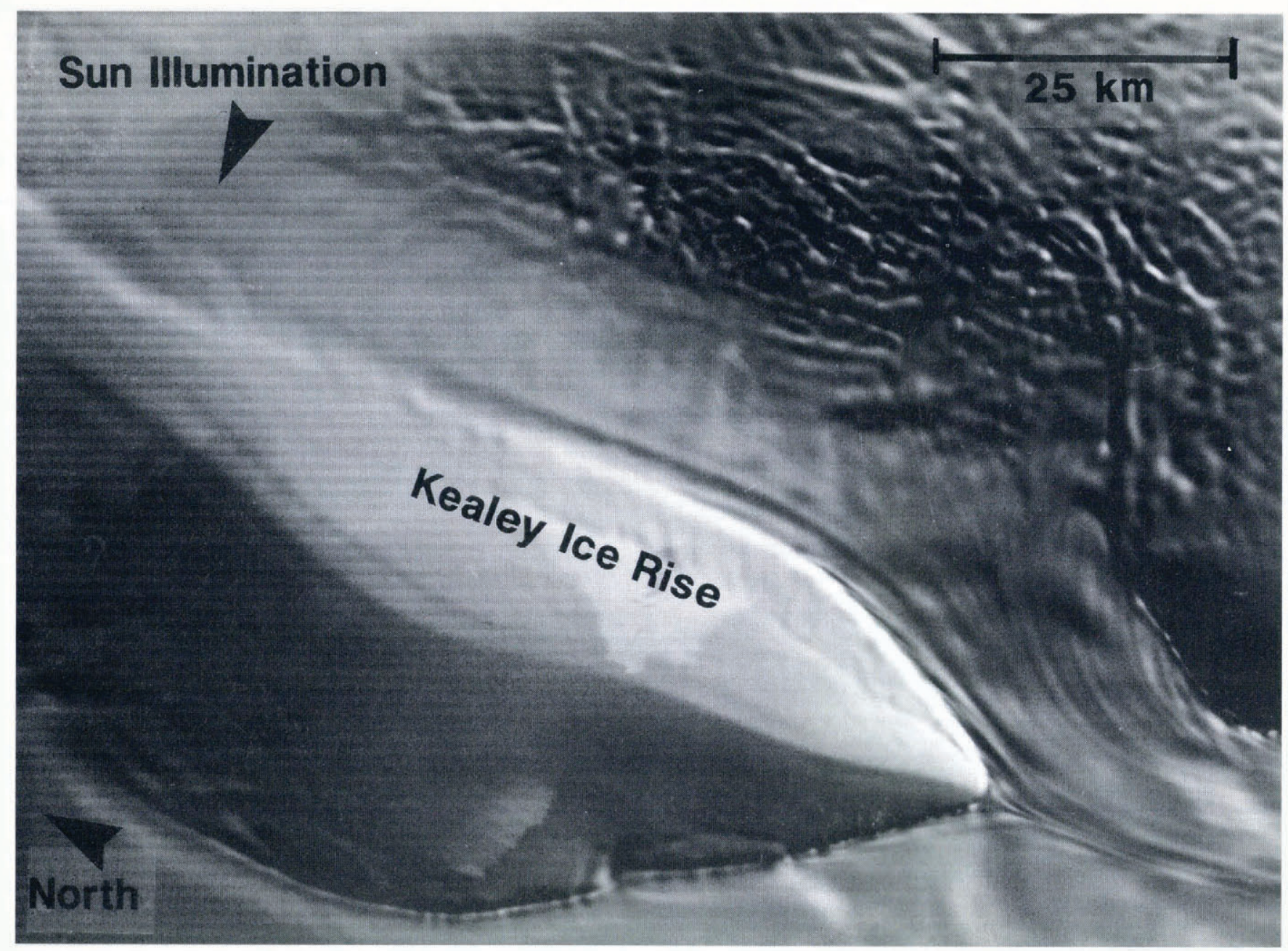

Fig. 2b. Sub-scene of Landsal TM image of Kealey Ice Rise (path/row 21.5/115, 30 January 1989). This sub-scene has been pholographically reproduced from the original pholographic product supplied by EOSAT.

understanding of the photometric function of the surface, a derivation of the topography (from a single image) by a process known as "photoclinometry" or "shape from shading" should be possible (Casassa, 1990); Cooper (1994) has shown that one algorithm, at least, can be successful under certain circumstances.

To make the best of these methods, a knowledge of the bi-directional reflectance function of the snow surface, or surface-elevation data for control, is required. It has been observed that albedo decreases with increasing solar elevation Choudhury and Chang, 1981). At high Sun elevation, snow tends to act as a diffuse reflector, nearly Lambertian, but at low elevations shows specular characteristics (Choudhury and Chang, 1981) where the dominant emergent angle is close to the incident angle. All the images considered in this study were taken with a Sun elevation of between $10^{\circ}$ and $20^{\circ}$, higher elevations generally causing instrument saturation over snow (Dowdeswell and McIntyre, 1987). Taking these factors together, the nadir viewing Landsat satellites, the low Sun elevation and the surface slopes of around 2 , the specular component of the reflection will be insignificant in the discussion below.

\section{THE STUDY AREA}

Fletcher Promontory is located at approximately $77^{\circ} 45^{\prime} \mathrm{S}$, $83^{\circ} \mathrm{W}$ (Fig. 1). It is an area of grounded ice over $200 \mathrm{~km}$ long with its crest $750 \mathrm{~m}$ above sea level, or between 300 and $500 \mathrm{~m}$ above the surrounding ice stream and ice shelf. Fletcher Promontory is bounded by two glaciers, Carlson Inlet to the northeast and Rutford Ice Stream to the southwest. Both contribute to the drainage of the West Antarctic ice sheet into the Ronne Ice Shelf (Fig. 2c). Fletcher Promontory has its own well-developed radialflow system and a single measurement of velocity close to the summit showed a flow rate of less than $30 \mathrm{~m} \mathrm{year}^{-1}$.

Surveys of the summit area were performed in the austral summers of 198586 and 1992-93. In 1992 -93, data were collected in four squares over the crest of Fletcher Promontory (Fig. 2c). A GPS receiver mounted on a Snowmobile collected kinematic GPS data, which were processed to give longitude, latitude and elevation. The relative precision of profile data collected by the method was found to be approximately $\pm 8 \mathrm{~cm}$ (Vaughan, 1994). Projecting the GPS data on to a Lambert Conformal Conic map projection, distances between data points could be computed and, since the study area is small, errors associated with the projection are insignificant. Data for three tracks perpendicular to the ice divide are shown in Figure 3.

Before analysing the profiles shown in Figure 3 in detail, it is worth considering them in simple terms. The position of the crest is not central in each of the profiles, indicating that the grid was not exactly aligned with the 


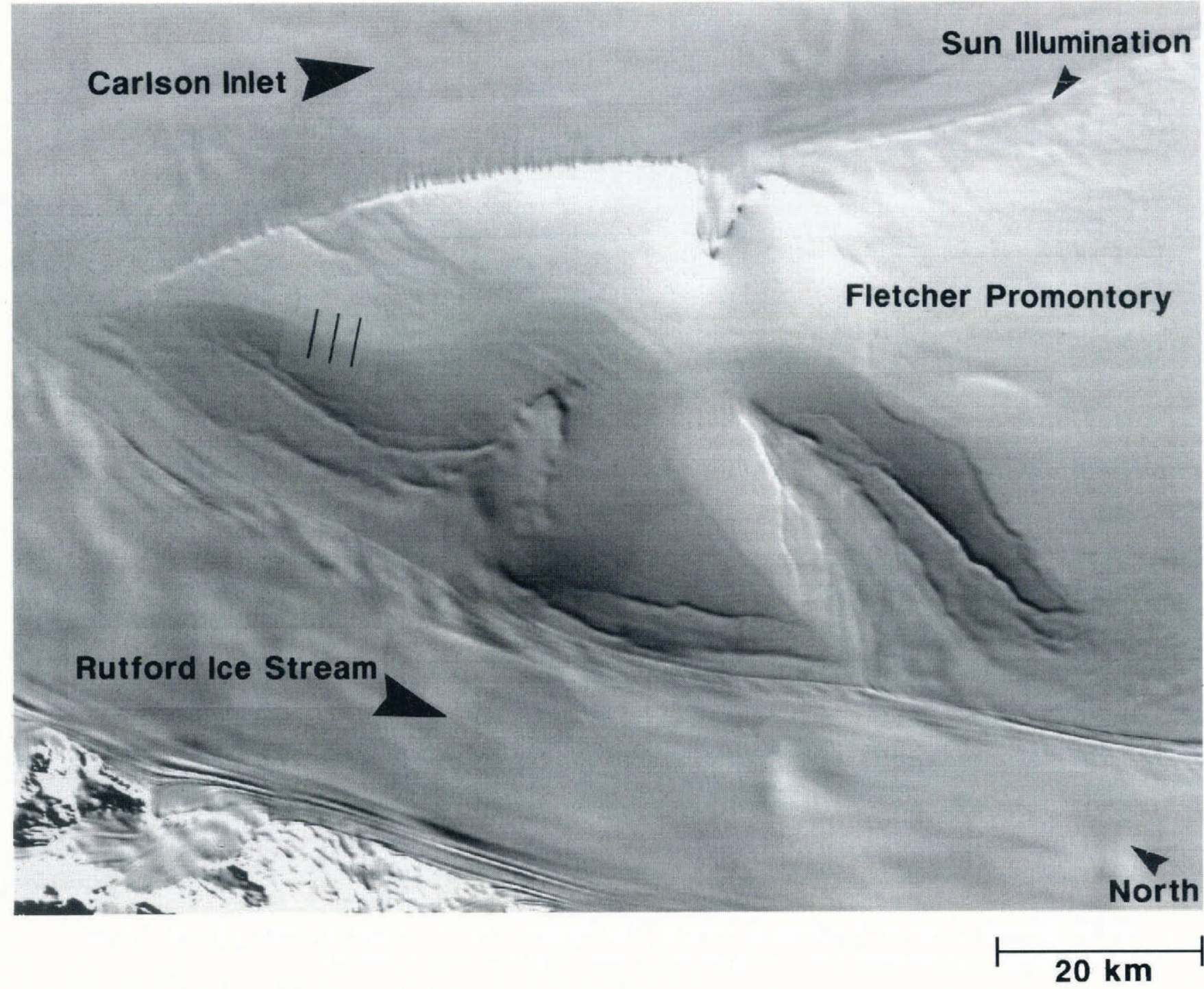

Fig. 2c. Sub-scene Landsat MSS image of Fletcher Promontory showing double ridge and location of GPS tracks (path/row 225/117, 3 February 1974, geocoded and reprojected to Lambert Conic Conformal by B. K. Lucchitta of the U.S. Geological Survey).

crest. This, at least in part, results from the low slopes near the crest, that make the position of the crest difficult to locate from the ground. Another noticeable feature of the profiles is the very slight concavity on the northeast (right) side of the crest. The same concavity appears on all three profiles, strongly suggesting it is a continuous feature parallel to the crest. In broad terms, we believe that this concavity is the cause of the apparent double ridge on the imagery but, to demonstrate convincingly that this is indeed the sole factor involved, we must proceed to show that the position and magnitude of the signal is compatible with our understanding of the mechanism of the image formation. We also note a similar but less pronounced linearity on the southwest (left) side of the ridge on the profiles.

\section{CORRELATION OF SLOPE PROFILES TO THE LANDSAT IMAGE}

A digital elevation model (DEM) was computed from the
GPS elevation data so that the Landsat image (Fig. 2c) could be registered to the surface. Under normal circumstances, registration could be achieved by matching coordinates of ground control points (GCP) identifiable in both image and DEM. This operation was performed on the whole scene by B.K. Lucchitta using the available ground control. However, the poor quality of this ground control and its poor distribution mean that image registration is no better than several hundred metres. Within the sub-scene on the crest of Fletcher Promontory, there are no suitable GCPs and a precise registration of image was attempted by an alternative method.

Pentland (1990) has shown that a linear approximation to the Lambertian scattering law is applicable (accurate to $10 \%$ ) where surface slopes are small (less than $\left.11^{\circ}\right)$. His formulation gives the image intensity $I(x, y)$ as

$$
I(x, y)=\rho \lambda\left[\cos \sigma+\frac{\partial z}{\partial x} \cos \tau \sin \sigma+\frac{\partial z}{\partial y} \sin \tau \sin \sigma\right] \ldots
$$




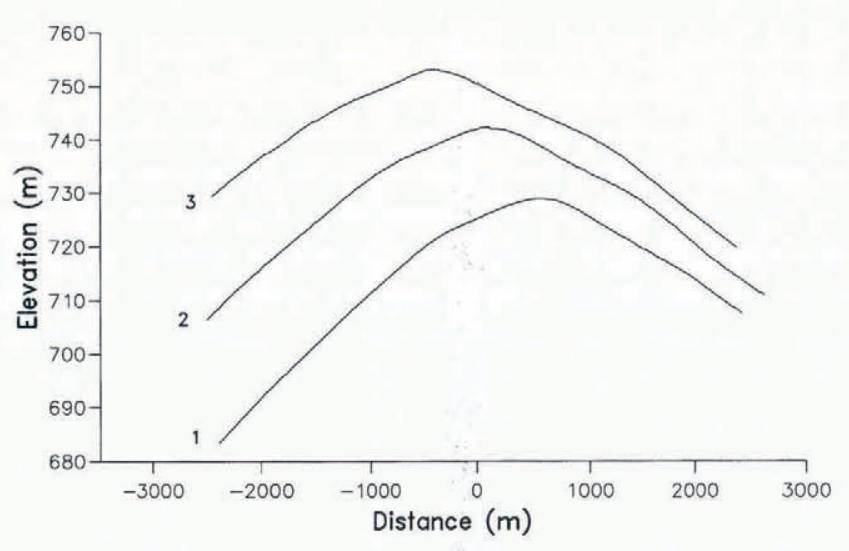

Fig. 3. Measured elevation profiles along GPS tracks across the summit regions. All profiles running from Rutford Ice Stream to Carlson Inlet. Tracks numbers from north to south. The double ridges occur between 300 and $1500 \mathrm{~m}$.

where the $x, y$ axes are horizontal, $z$ is the surface elevation, $\rho$ is the albedo of the surface, $\lambda$ is the strength of the illumination, $\tau$ is the angle the projection of the illumination on to the image plane makes with the $x$ axis, $\sigma$ is the angle the illumination makes with the vertical. If $\tau=0$, i.e. illumination is along the $x$ axis, then this reduces to

$$
I(x, y)=\rho \lambda\left[\cos \sigma+\frac{\partial z}{\partial x} \sin \sigma\right] \ldots
$$

This relation shows that, under the linear approximation, only the component of the surface slope parallel to the direction of illumination contributes to the image. In order to register the DEM to the image, we have therefore made a direct correlation of the surface slope parallel to the Sun azimuth with the image-brightness values, under a set of $x-y$ translations. The translation corresponding to the highest correlation coefficient indicated the best DEM/image registration. The shape of the correlation shows that co-registration was accurate to 0.92 of a pixel (around $50 \mathrm{~m}$ ) and there is a unique solution.

The positions of each elevation point along the original three tracks, within the original image, were then determined and the corresponding brightness values extracted. It is noted that, since the image/slope

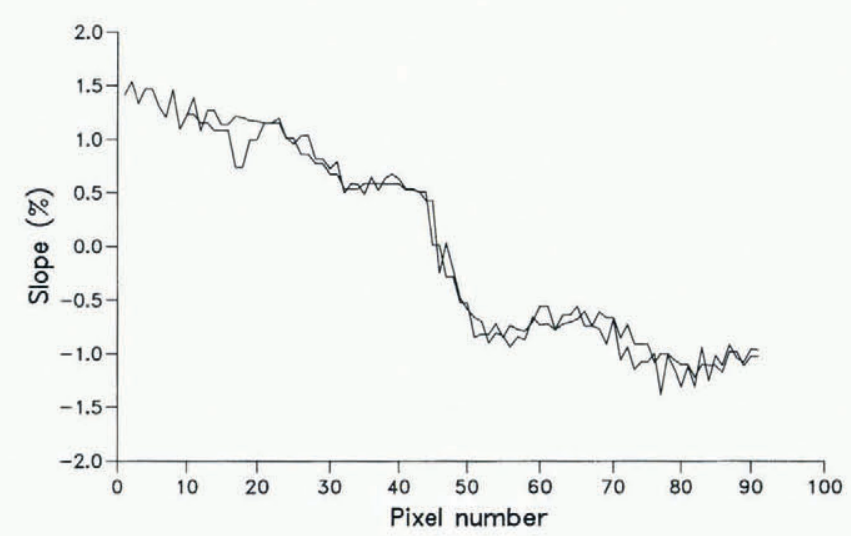

Fig. 4. Profiles of slope along GPS tracks across the summit of Fletcher Promontory. Tracks 2 and 3 only. correlation was performed only for translation and not rotation, a small residual error might remain due to any rotational error in the original re-sampled image.

Figure 4 shows profiles of slope along the direction of illumination for tracks 2 and 3 , both profiles showing a distinct depression at around pixel number 52. Accepting only the topographic data, and Pentland's linear approximation as an adequate description of the physical process, this is sufficient to indicate that we should expect a double ridge to appear in the imagery of Fletcher Promontory.

\section{DETAILED COMPARISON OF BRIGHTNESS VALUES AND SLOPES}

Having registered the image and the slope data, a regression analysis was performed to compare the brightness values $(\mathrm{BVs}$ ) and slope data for the whole sub-scene (Fig. 5). It shows a good correlation, indicating that the BVs are largely determined by the topography.

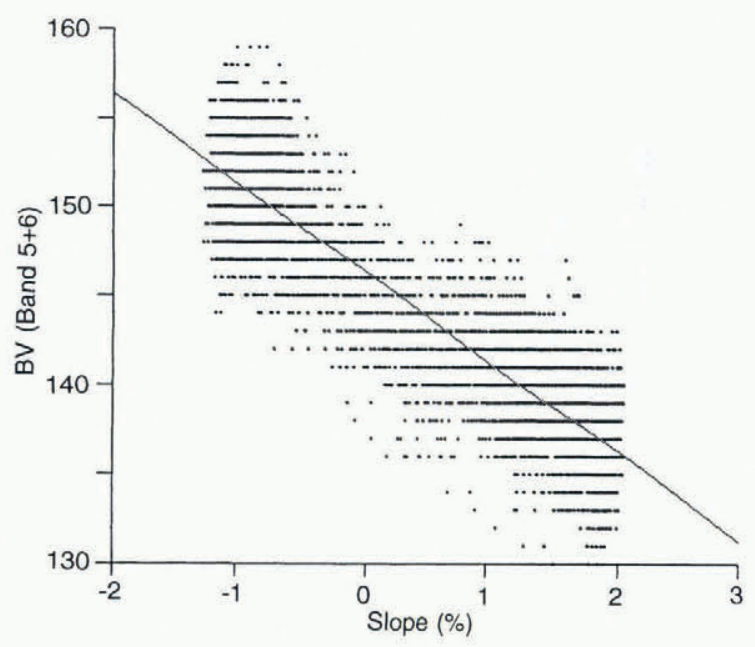

Fig. 5. Regression analysis of $B V$ and slopes for complete sub-scene. Correlation coefficient, $r^{2}=0.85$.

A feature of Landsat imagery over ice and snow is the low contrast of many images, often covering only a few quantization levels. This image (Fig. 2c) is quite typical, with only a low contrast along the profiles, and so the noise introduced by the sensor partially obscures the second ridge in the profile of brightness values. The slight depression in profiles of $\mathrm{BV}$, that corresponds to the second ridge we see in the imagery, is not clear through the noise. To reduce the noise level, a strip 20 pixels wide, centred on the track of the GPS data, was extracted from the image, and values were averaged across the strip. As a further measure, the profiles from bands 5 and 6 were added together (Fig. 6a) (for brevity only track 2 is shown), additionally suppressing the uncorrelated noise between the image bands (Vaughan and others, 1988).

Using the values obtained from the regression relation, modelled BVs could be predicted from the slope data. Figure $6 \mathrm{a}$ shows the image data and Figure 6b shows predicted BV profiles corresponding to GPS tracks 2 and 3. This procedure might be considered as following a 

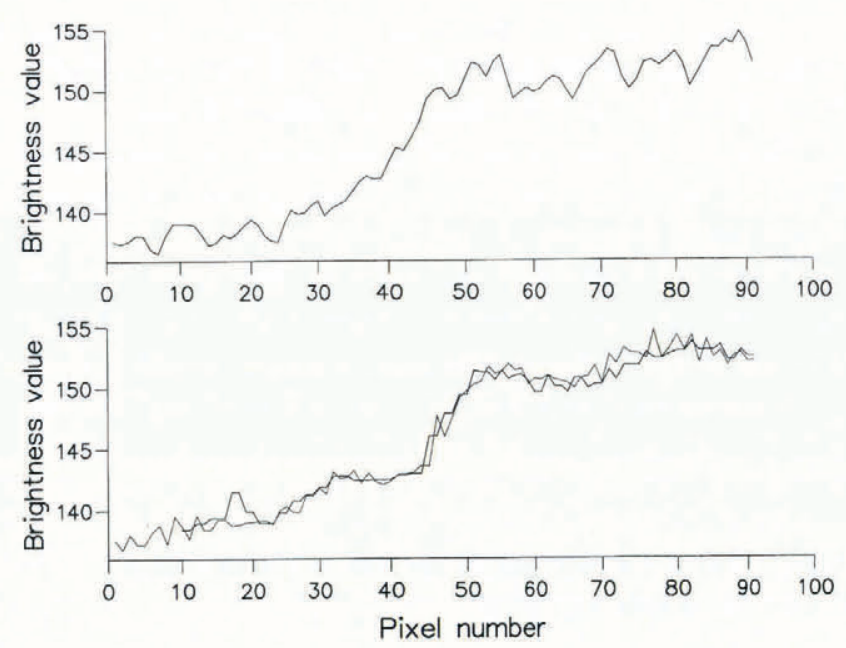

Fig. 6. Comparison of the actual and modelled imagebrightness values. a. Profiles of average image-brightness value extract from 20 pixel wide swath across the summit region of the sub-scene. Coincident with profiles of slope given in Figure 5 (track 2, MSS bands 5 and 6). b. Profiles of modelled brightness value derived from GPS slope profiles, tracks 2 and 3.

circular argument but in this case we are not attempting to verify the general theory but rather to test it. Figure 6 is simply intended to highlight any systematic difference between the actual BV profile and that which would be predicted from the GPS data. Comparing the original image profiles with the two modelled ones, the model appears to have achieved a very satisfactory result. The model clearly shows a drop in BV of 2 between pixel locations 60 and 70, corresponding to the second ridge, followed by a steady increase. The good match of the modelled and actual BV profiles indicates that the double ridge observed in the imagery is of topographic origin and it is the concavity close to the ridge that is responsible for the effect.

\section{OTHER FACTORS}

In this section, we attempt to show evidence that the two other factors potentially affecting the image representation of the ice-rise crests, accumulation and sastrugi, are not in this case significant.

The accumulation of snow across the crest of Fletcher Promontory was measured for the year 1986-87 using accumulation stakes. The data show an accumulation of around $0.9 \mathrm{~m}$ of snow. There is evidence of a slight decrease $(0.2 \mathrm{~m})$ on the northern slope but the variation between successive measurements is up to $0.3 \mathrm{~m}$. A more precise set of measurements could have been obtained from a set of pits or borehole studies of oxygen-isotope or beta-radioactivity and these might have shown subtle variations in accumulation rate. However, from the stake data, we cannot identify any gross variations in accumulation that coincide with the double-ridge features.

In addition to the profiles already discussed, one further kinematic GPS profile was collected. The method was similar to that used for the other profiles except that, in this case, the Snowmobile was driven at approximately
$1 \mathrm{~ms}^{-1}$ and the GPS data were logged at $1 \mathrm{~s}$ intervals. The profile was $1.4 \mathrm{~km}$ long and across the ice-rise crest. The aim of this experiment was to collect data that would allow any changes in the sastrugi field across the ice crest to be determined by measuring fine detail of the Snowmobile trajectory. The resulting profile showed that the amplitude of the sastrugi field was no greater than around $10 \mathrm{~cm}$. Unfortunately, the sastrugi signal was therefore somewhat contaminated by the $5 \mathrm{~cm}$ noise resulting from the GPS technique.

Having removed the general trend from the profile, it was linearly interpolated on to a $0.25 \mathrm{~m}$ spacing $(8500$ points). Fourier transforms of 512 point blocks of the data were then calculated. The method could be reasonably expected to yield data for surface roughness with spatial frequencies in the range $0.5-0.05 \mathrm{~m}^{-1}$ and, indeed, this part of the spectrum contained a large proportion of the total spectral energy. There was, however, no distinct change in the shape of the spectra across the ice divide and hence no evidence for a change in roughness spectrum that might show up in the imagery.

We consider that the only feature of the snow surface likely to cause a signal in the imagery that was not investigated at the study site was the small-scale roughness, including crystal-scale structure, at higher spatial frequencies than $0.5 \mathrm{~m}^{-1}$. Although large areas of the ice sheet appear to be homogeneous at this scale, there are certainly occasions in which crystal-scale changes caused by wind or Sun can cause significant changes in reflectivity over very short distances; an example can be seen in Figure 2b, on the sunny side of Kealey Ice Rise, where there is a patch of snow that appears to be much brighter than its surroundings. Such features do not, however, appear to be very long-lived and do not generally appear in repeated images of the same area. The double ridges on the main crest of Fletcher Promontory appear in repeated images of the same area. The double ridges on the main crest of Fletcher Promontory appear consistent on all five images we have examined spanning 1974-89 (Goodwin, 1993). Therefore, we consider it unlikely that such crystal-scale effects are responsible for the double-ridge features.

\section{SUMMARY OF ANALYSIS}

Double-ridge features are a common but by no means ubiquitous feature of linear ice divides on ice rises and similar features. The ice divide on Fletcher Promontory is a good (although not the strongest) example of the phenomenon. High-precision surface-elevation data were collected over the summit of Fletcher Promontory and, modelled considering the surface as a Lambertian scatterer, approximated by a linear function over the very low range of slopes encountered. The resulting modelled profiles satisfactorily reproduced the main features of the image profiles, both the shape of the crest and the double-ridge feature. The latter results from a subtle concavity close to the ridge. We conclude that the apparent double ridge observed in imagery can be explained entirely as a result of the topography and not by a change in snow-crystal fabric across the ridge, as was suggested by Martin and Sanderson (1980). 


\section{DISCUSSION}

For those interested in the ice sheet itself, there remains the question of what causes the concavity and linearity close to the ridge. And, furthermore, what can the presence or absence of such concavities tell us about the ice dynamics of the ridge?

Models of steady-state ice dynamics predict that, at least close to the summit, an ice divide should be symmetrically balanced, i.e. symmetrical in profile. This is certainly true for the four ice rises that were profiled by Martin and Sanderson (1980) and which do not show double-ridge features. Thus, the asymmetry exhibited by Fletcher Promontory would seem to imply non-steadystate conditions or, in other words, an active migration of the ridge in response to changing dynamic-boundary conditions (personal communication from R. C. A. Hindmarsh, 1994).

Weertman (1973) investigated the controls on the positions of ice divides and so indirectly the changes that might cause them to alter position. He showed that nonuniform surface accumulation, non-uniform bedrock and asymmetric basic sliding, could all have an effect in determining the equilibrium position. However, the basal ice is probably frozen to the bedrock beneath Fletcher Promontory and it is unlikely that a change in the bed morphology has occurred or that sliding is significant. Since Weertman found that very large changes in the accumulation rate pattern were required to cause even small movements in the ice divide, none of these explanations seems likely. Instead, we consider the last boundary, i.e. that with the surrounding ice shelf.

Fletcher Promontory is bounded to the south by Rutford Ice Stream, flowing at around $300 \mathrm{ma}^{1}$ and showing some "marginally significant" signs of acceleration (Frolich and others, 1989). To the north, it is bounded by Carlson Inlet which has a similar thickness, width and surface gradient as Rutford Ice Stream, and both occupy well-developed bedrock troughs. Carlson Inlet, however, currently flows at only $7 \mathrm{ma}^{-1}$. Observations led Frolich and others to conclude that it is a difference in basal conditions that causes the different flow regimes between these neighbouring glaciers. Since basal conditions may be prone to rapid change, we may speculate that Carlson Inlet may have ceased to stream in recent times. Since ice can only leave the ice-rise margins by being entrained into the ice-stream shear margins, and the amount of ice lost in this way must be controlled by the velocity of the ice stream, an event, such as the cessation of streaming on Carlson Inlet, would perhaps upset the equilibrium of Fletcher Promontory. A simple calculation, following the same reasoning employed by Weertman (1973), indicates that, under equilibrium conditions, the position of the ice divide has a linear dependence on the ability of the opposite margins to entrain ice. The effect of increasing the relative velocity of Rutford Ice Stream over Carlson Inlet might be to draw down the surface of the southern flank of Fletcher Promontory, displacing the ice divide to the north. One might speculate that the observed concavity and linearity are an indication of a northward migration of the ice divide in response to the cessation of streaming on Carlson Inlet. So far, we have compared surveys over the crest of Fletcher Promonotory in 1986 and 1993 but have found no evidence for ice-divide migration (Goodwin, 1993); repeat surveys in the future may confirm such a migration and perhaps determine a time-scale for the response.

\section{ACKNOWLEDGEMENTS}

We are grateful to C. Doake, R. Hindmarsh, G. Rees and A. Smith for their useful discussions, and to an anonymous reviewer whose comments improved the manuscript.

\section{REFERENCES}

Casassa, G, 1990. Photoclinometry of Ice Stream C, Antarctica. Report for 1990 Graduate Summer Program, Unizersities Space Research Association. Greenbelt, MD, NASA Goddard Space Flight Center.

Choudhury, B. J. and A. T. C. Chang. 1981. On the angular variation of solar reflectance of snow. J. Geophys. Res., 86 C1), 465472.

Cooper, A. P. R. 1994. A simple shape-from-shading applied to images of ice covered terrain. IEEE Trans. Geosci. Remote Sensing, 32 6), 1196-1198.

Dowdeswell, J. A. and N. F. McIntyre. 1987. The surface topography of large ice masses from Landsat imagery. J. Glaciol., 33 113), 16 23.

Eliason, P. T., L. A. Soderblom and P.S. Chavez. 1981. Extraction of topographic and spectral albedo information from multispectral images. Phologramm. Eng. Remole Sensing, 48 11), $1571-1579$.

Frolich, R. M., D.G. Vaughan and C.S. M. Doake. 1989. Flow of Rutford Ice Stream and comparison with Carlson Inlet, Antarctica. Ann. Glaciol.. 12, 51-56.

Goodwin, A. H. 1993. Albedo variations over Antarctic ice rises. M.Sc. thesis, University of Aberdeen.

Hall, D. K. and J. Martinec. 1985. Remote sensing of ice and snow. London, etc., Chapman and Hall.

Lucchitta, B. K., J. -A. Bowell, K. L. Edwards, E. M. Eliason and H. M. Ferguson. 1987. Multispectral Landsat images of Antarctica. U.S. Geol. Surv. Bull. 1696.

Martin, P.J. 1976. Antarctic ice rises. J. Glaciol., 17 (75), 141-144.

Martin, P.J. and T.J. O. Sanderson. 1980. Morphology and dynamics of ice rises. J. Glaciol., 2591$), 3345$.

Pentland, A. P. 1990. Linear shape from shading. Int. \%. Comput. Vision, 4. $153-162$.

U.S. Geological Survey. 1979. Landsat data users handbook. Revised edition. Washington, DC, U.S. Geological Survey.

Vaughan, D. G. 1994. Investigating tidal flexure on an ice shelf using kinematic GPS. Ann. Glaciol., 20, 372376.

Vaughan, D. G. and C.S. M. Doake. 1992. The use of satellite imagery over ice sheets. In Mather, P., ed. TERRA-1. Understanding the terrestrial emironment. London, Taylor and Francis, 920.

Vaughan, D. G., C. S. M. Doake and D. R. Mantripp. 1988. Topography of an Antarctic ice stream. In SPOT-l image utilization, assessment, resulls. Toulouse, CNES Cepadues-Editions, 167-174.

Warren, S. G. 1982. Optical properties of snow. Rev. Geoplyss. Space Phys., 20 1), 67-89.

Weertman, J. 1973. Position of ice divides and ice centers on ice sheets. J. Glaciol., 12 66, 353360. 